\title{
Design of Blast Furnace Crucibles by Means of the Nodal Wear Model
}

\author{
M. F. BARBÉS-FERNÁNDEZ, ${ }^{1)}$ E. MARINAS-GARCÍA, ${ }^{1)}$ E. BRANDALEZE ${ }^{2)}{ }^{2}$. PARRA-FIGUEROA, ${ }^{3)}$ \\ L. F. VERDEJA-GONZÁLEZ," G. A. CASTILLO-RODRIGUEZ ${ }^{4)}$ and R. COLÁS ${ }^{4)}$
}

\begin{abstract}
1) Siderurgia, Escuela de Minas, Universidad de Oviedo, Independencia 13, 33004 Oviedo, Spain. E-mail: siderurgia@uniovi.es $\quad$ 2) Instituto Argentino de Siderurgia, Av. Central y Calle 19 Oeste, Buenos Aires, Argentina. E-mail: brandaleze@siderurgia.org.ar 3 3) Departamento de Metalurgia, Universidad de Concepción, Barrio Universitario, Concepción, Chile. E-mail: rparra@udec.cl 4) Facultad de Ingeniería Mecánica y Eléctrica, Universidad Autónoma de Nuevo León, A.P. 149-F, 66451, San Nicolás de los Garza, N.L. Mexico. E-mail: rcolas@mail.uanl.mx
\end{abstract}

(Received on April 23, 2007; accepted on November 29, 2007)

\begin{abstract}
The Nodal Wear Model (NWM) is used to explain and quantify the causes for the occurrence of different corrosion profiles observed in the hearth of blast furnaces during their campaign, and, as a consequence it is possible to use the NWM to define the most appropriate refractory materials for designing and constructing blast furnace crucibles. The NMW is based in three critical parameters which are the temperature at the interface between pig iron and the refractory lining $\left(T_{i}\right)$, the temperature difference between such a point and at an adjacent node $\left(\Delta T_{i}\right)$, and the difference in temperature between the bulk liquid and that at the refractory-iron interface $\left(T^{\infty}-T_{j}\right)$. If the design and construction criteria rest upon reaching maximum durability of refractory linings, then, according to the NWM, all changes that minimize the values of $T_{i}$ and $\Delta T_{i}$, and maximize $T^{\infty}-T_{i}$ should be attempted.
\end{abstract}

KEY WORDS: blast furnace; crucible design; corrosion; modelling.

\section{Introduction}

It was believed at the end of the XXth century that production of pig-iron in blast furnaces would be replaced by more competitive means for producing iron. At present times, however, it has been proven that those forewarnings are not coming around due to the need to maintain the blast furnace technology within the iron and steel industry. This results as a consequence of low operative costs and high production capacity of blast furnaces. Reduction in the price of steel scrap can alter the balance of steel produced by basic oxygen furnaces (BOF) and electric arc furnaces (EAF); nowadays, raw steel produced by the blast furnace (BF)-BOF route remains at around $65 \%$.

A general consensus for guaranteeing the continuity of BF during the following years exists. ${ }^{1)}$ Nevertheless, a pessimistic outlook for the subsistence of blast furnaces remains, as is forecasted that control of nuclear fission, which can provide an unlimited amount of hydrogen, will be able to revolutionize the iron and steel industry, and could alter the role of blast furnaces within this industry. Until then, blast furnace technology has various challenges to meet before considering itself depleted, such as are the increase in air temperature and gradual enrichment of oxygen or the injection of various types of liquid, gas or solid fuels in the blast, as are the means to recover heat from molten slag.

Blast furnaces are considered to be strategic tools in the production of hot metal in modern iron and steel industry and are still able to attract attention to such a century-old process. Evolution of technology has occurred in recent decades allowing the increase of campaign duration fiveand even six-fold. ${ }^{2)}$ The actions that aim to control and prolong the operational life of blast furnaces are the following ones:

- Improvement in operational practices.

- Control of production and improvement in repair and maintenance technology.

- New designs of crucibles and blast furnaces.

Although none of these actions can guarantee by themselves maximum duration of the installations under high productivity rates, more attention is needed for the search of new designs for blast furnaces and other ancillary equipment, as such innovations provide the basis that allowed improvements in the operation of blast furnaces in recent decades. The most sensitive area, from a structural point of view, in a blast furnace is the crucible, which exerts the greatest influence in its operational life.

The adjustment in composition and the separation and transfer of the various elements present in the molten phases (hot metal and slag) takes place in the crucible. This zone is the most delicate area of the furnace, so it is normal practice to shut down the installation when repairing or reconstructing the crucible, causing huge economical losses. Reconstruction of the crucible translates in many cases into building a new blast furnace. Therefore, iron and steel companies try to operate the blast furnace for as long as possible before repairing.

Due to the above mentioned reasons, the main efforts to 
find alternatives that improve the operational life of blast furnaces result in improvements around the crucible. Within this line of work, analyses of refractory materials used for relining, as well as the study of refrigeration systems play an important role. Together with these innovations, it is of interest to consider the effect that the geometry of the installation (size, inclination of walls, etc.) and the position and number of tap holes exert on the life of the blast furnace.

Leaving aside the external construction of the crucible (refrigeration and drainage systems), there is the added difficulty for finding the best design to reduce repairing and installation times. Although there are numerous alternatives that can be used for designing hearths, the time available limits the possibilities that can be put into practice. Due to the time-scale of blast furnace campaigns, it is difficult to assess the success of modifications in the refractory lining until the end of the campaign is reached, and this is often as long as ten or fifteen years. Therefore, the practical conclusions of changes made in the design or in the layout and quality of refractory materials can only be confirmed at the end of this time. ${ }^{2)}$ It is evident that selecting a given design goes together with the risk of operating the furnace for more than ten years with the materials available at the time of construction. It is not strange that traditional refractory linings are preferred over alternative new designs. Moreover, a proper and technically correct design might fail due to incorrect start-up or to undesirable operational practices occurring throughout the life of the furnace.

\section{Modelling}

Selecting the proper design for a crucible require criteria different than trial and error. Experience obtained from low temperature physical models, mathematical modelling and refractory corrosion tests can provide such information. The present study focus on design criteria derived from computational methods used to simulate different conditions occurring within the furnace. The results obtained by these methods are compared with data obtained from corresponding industrial conditions and provide the numerical values for the heat transfer coefficients of slag in contact with the refractory walls, temperature distribution within the crucible and the refractory layer, etc. Recent developments of specialised hardware and software allow modelling the different mechanisms that take place in the hearth with the precision that only a few years ago seemed impossible to reach. It is feasible that advances in computing capacity will continue over the following years, providing for the tools to improve the design and control of these installations.

The present work describes the Nodal Wear Model (NWM), which was conceived as a tool to interpret and quantify different corrosion phenomena that affect the refractory layer in contact with molten metal. NWM was designed to simulate corrosion profiles in blast and electric furnace crucibles, and has been recently applied to the analysis of wear in Pierce-Smith copper converter coatings. ${ }^{3-7)}$ However, one aim of this study is to make a much greater use of NWM by using its methodology to help decision making in selecting the material layout which should be most adequate for use in crucibles. NWM is incorporated into a finite element code, COSMOS/M in the present case, as this software provide the solution for the differential equations that describe the energy and mass transfer within the crucible.

The chemical corrosion rate, $v_{\text {cor- } q / i}$ at a given point of the refractory-slag interface (node, $i$ ) is a function not only of the absolute temperature at the node $i, T_{i}$, but also of the difference in temperature between that node and its adjacent, $i+1, \Delta T_{i}$. That is:

$$
v_{\text {cor- } q / i}=f\left(T_{i} ; \Delta T_{i}\right) \text {...... }
$$

The temperature distribution in the blast furnace hearth can be obtained at any moment of the campaign by means of thermocouples and heat flux sensors installed while refractory is placed, and this information help to calibrate the results of mathematical models. A series of criteria can be set to study wear of the refractory bricks. In the present case, the value of $1150^{\circ} \mathrm{C}$ is used for carbon-based materials and that of $1350^{\circ} \mathrm{C}$ for materials from the $\mathrm{SiO}_{2}-\mathrm{Al}_{2} \mathrm{O}_{3}$ system. $^{8-11)}$

The study of various chemical erosion mechanisms occurring to refractory materials in blast furnace crucibles, or in any other pyrometallurgic system, has to consider the existence of a boundary layer at the molten metal and refractory interface. Study of erosive mechanisms can be omitted by neglecting this interface layer, which is only 10 to $20 \mathrm{~mm}$ in depth; the temperature at the interface can be associated to that of the molten metal, which can be measured experimentally. Models based on the finite element or in computational fluid dynamics can be used to predict the temperature distribution or the corrosion profile of the refractory lining through the campaign using an uniform temperature of reference, which is related to that of molten metal within the crucible (between $1450^{\circ} \mathrm{C}$ and $1550^{\circ} \mathrm{C}$ ). However, corrosion rates predicted at the nodal points result uniform and far greater than those actually occurring.

The problem with the nodal temperatures at the interface between refractory and molten metal, $T_{i}$ in Eq. (1), is that they cannot be measured experimentally. However, the temperature at the interface is a function of the heat transfer coefficient at the boundary layer in contact with the refractory, $h_{\mathrm{g}}$, which depends on several parameters:

$$
h_{\mathrm{g}}=f\left(T^{\infty}-T_{i} ; \delta(T) ; n_{i} ; L\right) .
$$

where $T^{\infty}-T_{i}$ is the difference in temperature between the molten metal (which can be measured experimentally) and that at node $i$, of the interface, $\delta(T)$ is the thickness of the thermal boundary layer, $L$ represents the lineal dimension characteristic of the system being studied (diameter of the crucible or height of a wall) and $n_{i}$ represents the thermophysical properties and characteristic of molten metal (specific heat, density, viscosity and thermal conductivity, etc.).

In short, the nodal temperatures, $T_{i}$, are used to calculate the magnitude of corrosion attack at every point of the refractory-molten metal interface. Quantitatively, chemical corrosion of the hearth layer is determined assuming convective and diffusional phenomena, calculated with the equations given in detail in Table $1 .^{11-13)}$ Coupling the thermal profiles with those derived from chemical corrosion at each node of the interface with time constitutes the basic 
Table 1. Parameters and equations that are used to compute the wear of refractory in contact with molten iron.

\begin{tabular}{|c|c|c|}
\hline \multicolumn{3}{|c|}{ Corrosion due to diffusion. } \\
\hline \multicolumn{2}{|c|}{$v_{c o r-q-d / i}(m / s)=B L^{-1 / 2} D_{i / c . a c t}^{11 / 12} \rho_{i}(F e)^{1 / 6} \mu_{i}(F e)^{-1 / 6}[\%$ c.act $-\% c . a c t=$} & $\left.t^{=}\right]_{i}\left(\frac{\rho_{i}(\mathrm{Fe})}{\rho_{g}}\right)\left(\frac{100}{\% \mathrm{~cm}}\right)$ \\
\hline \multicolumn{3}{|c|}{ Corrosion due to convection. } \\
\hline \multicolumn{2}{|c|}{$v_{c o r-q-c / i}(\mathrm{~m} / \mathrm{s})=A L^{-1 / 2} D_{i / c . a c t}^{2 / 3}\left(\frac{\Delta \rho_{i}(\mathrm{Fe})}{\rho_{i}(\mathrm{Fe})}\right)^{1 / 6}\left[\% \text { c.act }-\% \text { c.act }{ }^{=}\right]_{i}$} & $\left(\frac{\rho_{i}(\mathrm{Fe})}{\rho_{g}}\right)\left(\frac{100}{\% c m}\right)$ \\
\hline \multicolumn{2}{|l|}{ Parameter } & Units \\
\hline$A$ & $8.80 \cdot 10^{-3}$ & $\mathrm{~m} \cdot \mathrm{s}^{-1}$ \\
\hline$B$ & $2.50 \cdot 10^{-3}$ & $\mathrm{~s}^{-1 / 4}$ \\
\hline$\mu_{i}(\mathrm{Fe})$ & $(24-0.0102 \boldsymbol{T}(\boldsymbol{K})) \cdot 10^{-3}$ & $\mathrm{~Pa} \cdot \mathrm{s}$ \\
\hline$\rho_{i}(\mathrm{Fe})$ & $8503-0.93 \boldsymbol{T}(\boldsymbol{K})$ & $\mathrm{kg} \cdot \mathrm{m}^{-3}$ \\
\hline \multirow{2}{*}{$D_{\text {c.act }}$} & $D_{S i}=5.1 \exp \left(-\frac{4607}{T(K)}\right) \cdot 10^{-8}$ & \multirow{2}{*}{$\mathrm{m}^{2} \cdot \mathrm{s}^{-1}$} \\
\hline & $D_{C}=7.17 \exp \left(-\frac{6259}{T(K)}\right) \cdot 10^{-7}$ & \\
\hline$\rho_{g}$ & $\begin{array}{c}2000 \text { (fireclay); } \\
3200 \text { (SIALON); } \\
1800 \text { (carbon - graphite) }\end{array}$ & $\mathrm{kg} \cdot \mathrm{m}^{-3}$ \\
\hline$\% \mathrm{~cm}$ & SIALON $=33 \%$ & Carbon $=100 \%$ \\
\hline$\% c . a c t=$ & $\% S i^{=}=18862 \exp \left(-\frac{81907}{T(K)}+41.98\right)$ & $\begin{array}{c}\% \boldsymbol{C}=2.19 \boldsymbol{T}\left({ }^{\circ} \mathrm{C}\right) \cdot 10^{-3}+ \\
1.734\end{array}$ \\
\hline \multicolumn{2}{|r|}{$\% \mathrm{Si}=0.4$} & $\% C=4.5$ \\
\hline$L$ & Diameter of the hearth (nodes of the bottom) & $\begin{array}{l}\text { Height of the nozzles } \\
\text { (nodes of the wall) }\end{array}$ \\
\hline
\end{tabular}

working tool aimed for designing crucibles able to achieve longer campaigns with increased productivity.

The nodal temperatures throughout the interface with molten metal vary with time while the campaign lasts. Normally, the temperature tends to decrease as the residual thickness of the refractory is reduced in different zones of the hearth. If the NWM criteria are applied to a blast furnace hearth in operation, the thermal conditions at the refractory interface could be obtained in real time, as well as heat transfer coefficients and the thickness of the associated thermal boundary layer at each node.

The present study simulates the resistance of refractory materials against chemical corrosion of molten metal, and it is necessary to carry out the simulation in different time intervals, so that the magnitude of nodal wear, $\Delta e_{i}$, for each interval can be expressed by:

$$
\Delta e_{i}=v_{\text {cor- } q / i} \Delta t
$$

where $\Delta t$ is the time elapsed at each of the intervals being considered. A safety criterion for the total time of operation can be that the remaining refractory thickness is higher than $10 \%$ of the original thickness.

Figure 1 summarizes the parameters used to compute the wear rate of refractory materials installed in the hearth, together with three different types of profiles found to occur during operation. The thermal boundary layer is indicated as $\delta(T)$ in this figure. The heat transfer coefficient at the interface $\left(h_{\mathrm{g}}\right)$ is computed at the end of each cycle $(\Delta t)$ from the value at that particular time $\left(h_{i}\right)$, the thermal conductivity of the molten iron $(\lambda)$ and the thermal boundary layer. Wear profiles normally encountered in blast furnace crucibles (known as mushroom, elephant foot and central pool $)^{3,4,14)}$ are illustrated in Fig. 1.

\section{Results and Discussion}

Figure 2 presents the schematic diagrams of four differ-

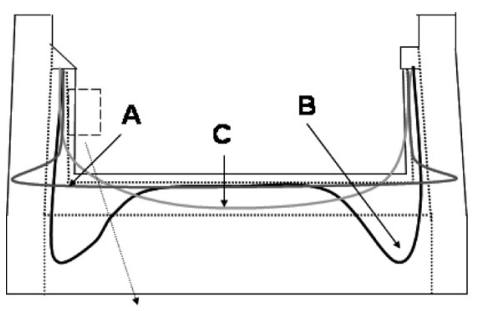

A: Mushroom B: Elephant foot C: Central pool

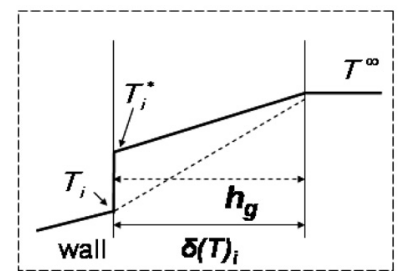

$\boldsymbol{h}_{g}=\left(\frac{\lambda}{\delta(T)}\right) \pm \boldsymbol{h}_{i}$

Thermal profile at the wall

Fig. 1. Parameters used to compute wear and schematic diagram of different worn profiles.

ent models constructed to evaluate the effect of using refractory materials of different thermophysical properties. The models were constructed with an internal wall $100 \mathrm{~mm}$ thinner at the right hand side to evaluate the effect of bleeding the furnace, which results in accelerated degrading. The thermophysical properties of the materials used to construct the models are shown in Table 2. The external walls in all the models considered in Fig. 2 are assumed to be made of a medium thermal conductivity graphite $\left(22 \mathrm{~W} \mathrm{~m}^{-1} \mathrm{~K}^{-1}\right)$, the vertical walls and the top portion of the crucible in models identified as HAB1, HAB3 and HAB4 are made of sialon $\left(3.4 \mathrm{~W} \mathrm{~m}^{-1} \mathrm{~K}^{-1}\right)$, the bottom portion of the crucible in HAB1 and HAB4 is made of anthracite $\left(12 \mathrm{~W} \mathrm{~m}^{-1} \mathrm{~K}^{-1}\right)$, whereas that zone in HAB3 is made of the medium conductivity graphite; the whole hearth of HAB5 is made of anthracite. High conductivity graphite $\left(44 \mathrm{~W} \mathrm{~m}^{-1} \mathrm{~K}^{-1}\right)$ is added to the corners of models HAB3, HAB4 and HAB5. It should be noticed that one of the external walls of HAB3 is made of anthracite, as it is desired to evaluate the effect of 

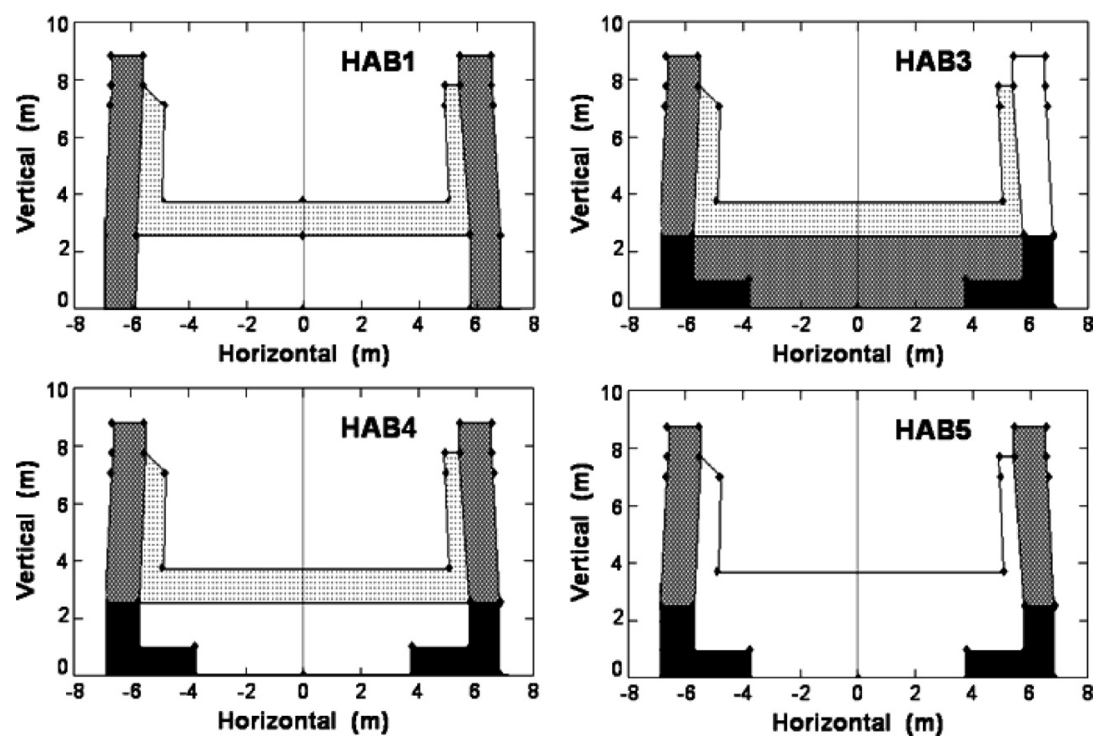

Fig. 2. Schematic diagrams of four different models constructed to evaluate the use of refractory materials of different thermophysical properties.

Table 2. Thermophysical properties of the refractory materials used in Figs. 2 and 3.

\begin{tabular}{|c|c|c|c|c|}
\hline Material & $\begin{array}{c}\lambda .\left(\mathrm{W} \cdot \mathrm{m}^{-1} \cdot \mathrm{K}^{-1}\right) \\
\text { thermal } \\
\text { conductivity }\end{array}$ & $\begin{array}{c}\rho_{g}\left(\mathrm{~kg} \cdot \mathrm{m}^{3}\right) \\
\text { apparent } \\
\text { density }\end{array}$ & $\begin{array}{c}\% \mathrm{~cm} \\
\% \text { first } \\
\text { component }\end{array}$ & $\begin{array}{l}\text { Chemical } \\
\text { composition }\end{array}$ \\
\hline 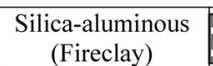 & 1.4 & 3200 & 30 & $\begin{aligned} \mathrm{Al}_{2} \mathrm{O}_{3} & =45 \% \\
\mathrm{SiO}_{2} & =50 \%\end{aligned}$ \\
\hline $\begin{array}{l}\text { SIALON High } \\
\text { Nitriding }\end{array}$ & 3.4 & 3200 & 33 & $\begin{array}{c}\mathrm{Al}_{2} \mathrm{O}_{3}=85 \% \\
\mathrm{~N}=6 \%\end{array}$ \\
\hline $\begin{array}{c}\text { Carbon-Anthracite } \\
\text { Low } \lambda\end{array}$ & 12 & 1800 & 100 & $\mathrm{C}>90 \%$ \\
\hline $\begin{array}{l}\text { Carbon-Graphite } \\
\text { Medium } \lambda\end{array}$ & 22 & 1800 & 100 & $\mathrm{C}>90 \%$ \\
\hline $\begin{array}{c}\text { Carbon-Graphite } \\
\text { High } \lambda\end{array}$ & 44 & 1800 & 100 & $\mathrm{C}>90 \%$ \\
\hline
\end{tabular}
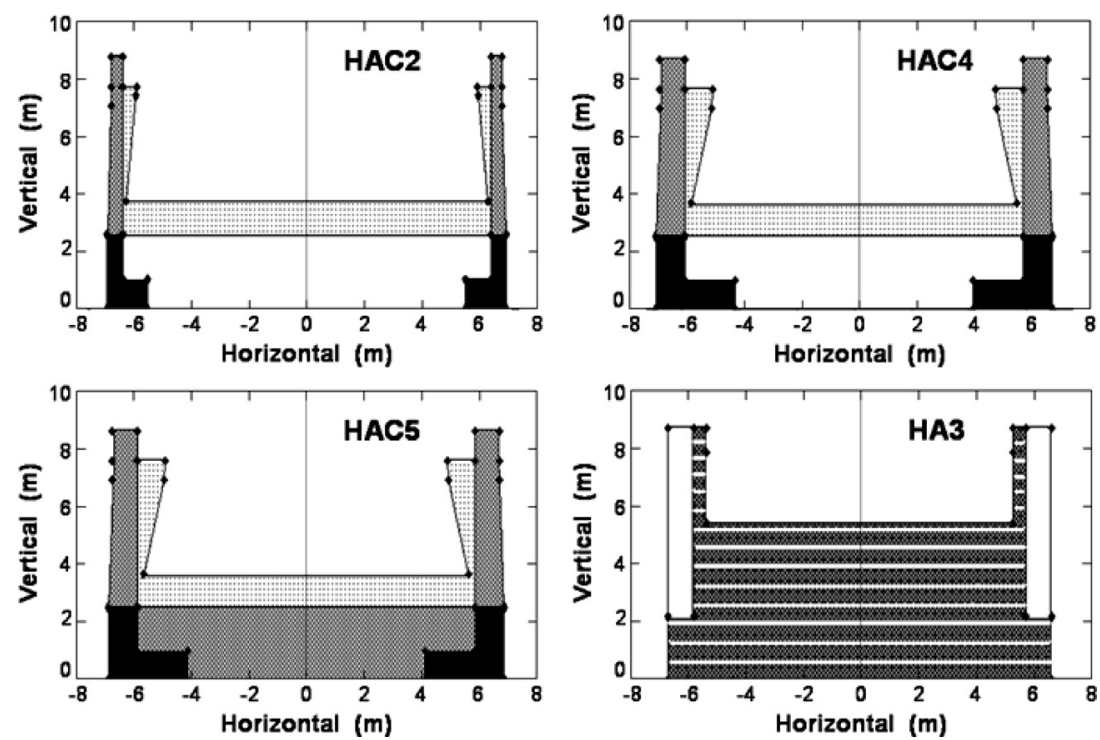

Fig. 3. Schematic diagrams of four different models constructed to evaluate the geometry of the hearth and the use of different refractory materials.

having materials with different properties.

Figure 3 shows different models developed to evaluate the effect of geometry combined with the use of different materials. HAC2 and HAC4 use the same materials as HAB4, but the internal walls are inclined; the wall thickness of HAC2 is half as that of HAC4. HAC4 and HAC5 have the same geometry, but the later one has the bottom made of carbon graphite. HA3 corresponds to a different design, as the walls are vertical, and it is made almost exclusively of fireclay $\left(1.4 \mathrm{~W} \mathrm{~m}^{-1} \mathrm{~K}^{-1}\right)$, although the external walls are made of anthracite.

Figures $\mathbf{4}$ and $\mathbf{5}$ show the wear profiles after different 

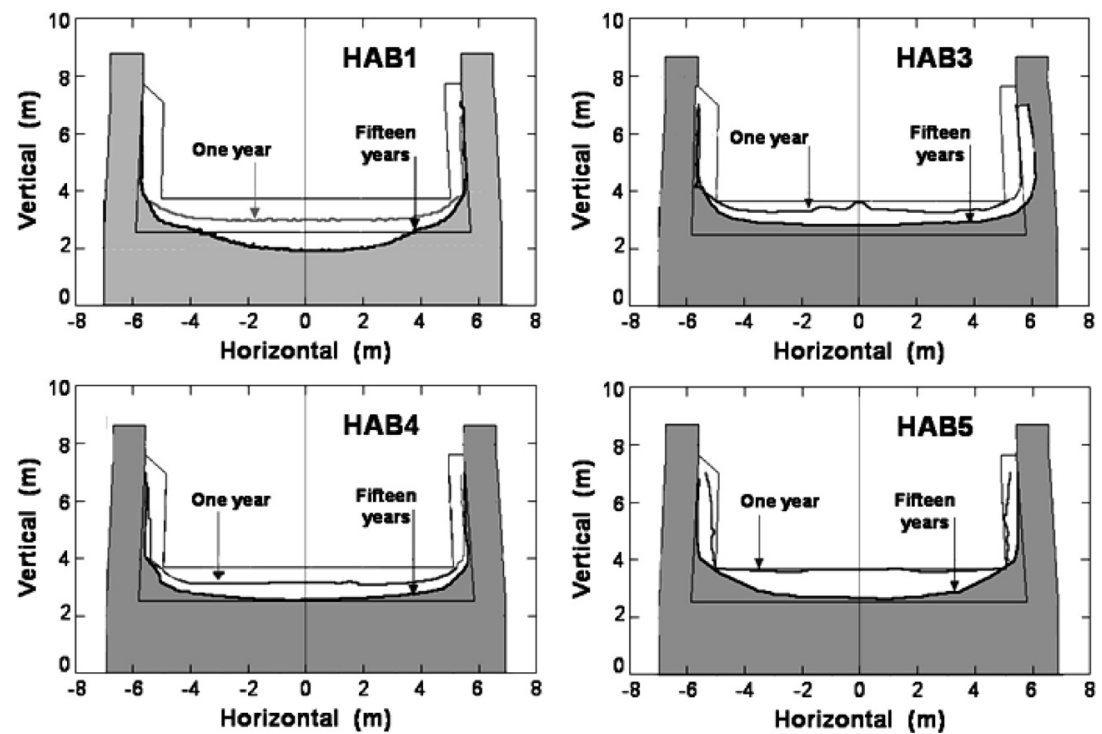

Fig. 4. Wear profiles after one and fifteen years in the hearths shown in Fig. 2.
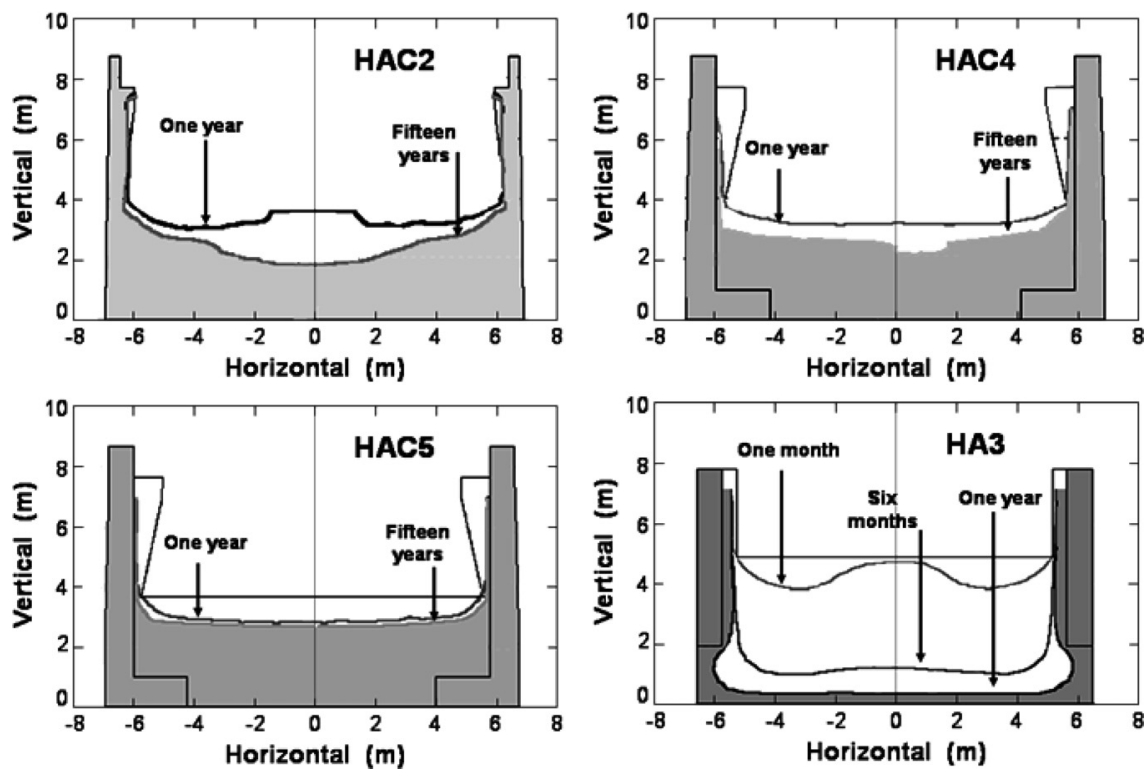

Fig. 5. Wear profiles after one and fifteen years in the hearths shown in Fig. 3.

time have elapsed for the models shown in Figs. 2 and 3. It can be considered that NWM is able to reproduce the different corrosion profiles that occur in crucibles during campaigns of a blast furnace, ${ }^{3,4,14)}$ see Fig. 1. Simulation of anthracite hearths with inadequate refrigeration at the bottom develop a mushroom wear profile in a very short period of time that results in perforation below the tap-hole level, ${ }^{3)}$ as it is shown to occur in the model for HA3 in Fig. 5.

NWM is used to evaluate the wear rate to which refractory material is subjected to. Tables 3 and $\mathbf{4}$ show the results computed for configurations shown in Figs. 2 and 3. Table 3 presents the maximum values detected at any point in the interface at the start of the campaign, after 15 years (assuming that this is the operational life) and the maximum value detected at any time. Table 4 shows the corresponding values averaged on the interface for similar conditions. The times and rates of wear encountered when the interface reaches a different refractory material are indicated in Tables 3 and 4. NWM confirms that the high corrosion rates to which refractory materials are subjected at the start of the campaign weakens over the years, reaching a much reduced rate that depends on the characteristics, quality and layout of the materials used, ${ }^{4,15,16)}$ Tables 3 and 4. Table 5 indicates that the rates of corrosion of materials installed in the blast furnace are different than those reported in laboratory trials. In agreement with these results, it can be considered the inadequacy of layout criteria based on solely static or dynamic corrosion tests. ${ }^{17,18)}$

NWM can be used to analyze and evaluate different alternatives being used for the construction of crucibles. The characteristics shown in Figs. 2 to 5 were modelled to obtain information related to design criteria:

1. Evaluation of the effect that positioning and location of refractory materials available exert on crucible life; it is of particular interest to know which of the common used criteria, ceramic cup or thermal model, is more adequate.

2. Evaluation of the effect of designing criteria used in America (thin walls and bottom made from thick carbonaceous materials with little refrigeration) or in Eu- 
Table 3. Maximum values of the corrosion rate $\left(\mathrm{m} \cdot \mathrm{s}^{-1}\right)$ for different models.

\begin{tabular}{|c|c|c|c|c|c|c|}
\hline \multirow{2}{*}{ Model } & \multirow{2}{*}{ Start } & \multicolumn{2}{|c|}{ Change of material } & \multirow{2}{*}{$\begin{array}{c}\text { After } 15 \\
\text { years }\end{array}$} & \multicolumn{2}{|c|}{ Maximum value } \\
\hline & & Rate & Time & & Rate & Time \\
\hline HAB1 & $2.93 \times 10^{-7}$ & $1.55 \times 10^{-7}$ & 210 days & $3.08 \times 10^{-9}$ & $8.53 \times 10^{-7}$ & 150 days \\
\hline HAB3 & $2.72 \times 10^{-7}$ & $2.19 \times 10^{-7}$ & 600 days & $1.65 \times 10^{-8}$ & $5.30 \times 10^{-7}$ & 45 days \\
\hline HAB5 & $2.54 \times 10^{-8}$ & - & - & $4.22 \times 10^{-9}$ & $3.23 \times 10^{-8}$ & 3 years \\
\hline HAC4 & $1.26 \times 10^{-7}$ & - & - & $2.38 \times 10^{-9}$ & $3.08 \times 10^{-7}$ & 23 days \\
\hline
\end{tabular}

Table 4. Average values of the corrosion rate $\left(\mathrm{m} \cdot \mathrm{s}^{-1}\right)$ for different models.

\begin{tabular}{|c|c|c|c|c|c|c|}
\hline \multirow{2}{*}{ Model } & \multirow{2}{*}{ Start } & \multicolumn{2}{|c|}{ Change of material } & \multirow{2}{*}{$\begin{array}{c}\text { After } 15 \\
\text { years }\end{array}$} & \multicolumn{2}{|c|}{ Maximum value } \\
\hline & & Rate & Time & & Rate & Time \\
\hline HAB1 & $1.02 \times 10^{-8}$ & $1.59 \times 10^{-8}$ & 210 days & $2.22 \times 10^{-10}$ & $6.63 \times 10^{-8}$ & 150 days \\
\hline HAB3 & $1.08 \times 10^{-8}$ & $5.39 \times 10^{-8}$ & 600 days & $3.23 \times 10^{-9}$ & $7.42 \times 10^{-8}$ & 45 days \\
\hline HAB5 & $2.85 \times 10^{-8}$ & - & - & $6.66 \times 10^{-10}$ & $3.17 \times 10^{-8}$ & 3 years \\
\hline HAC4 & $3.93 \times 10^{-8}$ & - & - & $1.27 \times 10^{-10}$ & $3.93 \times 10^{-8}$ & 23 days \\
\hline
\end{tabular}

Table 5. Comparison of corrosion behaviour observed in blast furnaces and that from static tests.

\begin{tabular}{|c|c|c|}
\hline & Blast furnace & Laboratory static tests \\
\hline Corrosion rate $\left(\mathbf{m} \cdot \mathbf{s}^{-1}\right)$ & $10^{-9}-10^{-7}$ & $10^{-7}-10^{-5}$ \\
\hline State of corners & High corrosion & Almost no corrosion \\
\hline $\begin{array}{c}\text { Relation with thermal } \\
\text { conductivity }\end{array}$ & $\begin{array}{c}\text { Increase of corrosion with the } \\
\text { decrease of conductivity }\end{array}$ & $\begin{array}{c}\text { Increase of corrosion with the } \\
\text { increase of conductivity }\end{array}$ \\
\hline
\end{tabular}

rope (thick walls and bottom).

3. Evaluation of the effect of walls with different degrees of inclination and thickness, or constructed in stair manner.

NWM indicates that designing the hearths using the ceramic cup or the thermal model (crucible made of carbonaceous materials with different thermal characteristics) does not exert a marked different, see models HAB4 and HAB5 in Fig. 4, although the solution for the thermal model, HAB4, provides for less wear at the central pool of the crucible than in those constructed following the ceramic cup criterion, HAB1 and HAB5, although, from the point of productivity, such wear contributes to increments the production rate of iron. It is not clear how to interpret the results from modelling designs based on the ceramic cup criteria, as most industrial data are inconsistent, as there are reports indicting operation for a number of years without damage, and cases in which the blast furnace has to be stop due to perforation. The rates of corrosion predicted by NWM, shown in Tables 3 and 4, for designs based in the thermal model are more consistent than those for blast furnaces designed around the ceramic cup, even in the case in which the dead man laying at the bottom of the crucible does not cover the whole diameter of the furnace, Fig. 6 . Use of ceramic cup on top of carbonaceous materials have shown to cause radial contraction and vertical dilation that does not allow for the development of a proper joint between the different materials and reduce the operational life of the ceramic cup to less than five years. ${ }^{19)}$

NWM reproduces improvements obtained by using refrigeration at walls and bottom; following the same trend, NWM shows that the use of materials with higher thermal conductivity reduces the risk of developing mushroom or elephant foot profiles, see Fig. 1, within the crucible; the profiles predicted for models $\mathrm{HAB} 1, \mathrm{HAB} 3, \mathrm{HAB} 4$ and HAB5 in Figs. 2 and 4 and HAC4 and HAC5 in Figs. 3 and 5 are of the central pool type. Old blast furnaces relied on the use of fireclay for the crucible, with the consequence of accelerated wear and development of mushroom type profiles; see HA3 in Figs. 3 and 5. The size of the hearth af- fects the corrosion rates predicted by NWM; different runs were carried out modifying the diameter of the crucible, it was found that such a rate increases when the diameter is below $9 \mathrm{~m}$, confirming observations that big blast furnaces are able to operate longer than smaller ones. ${ }^{20)}$

It was found that the American criterion for design enhances the central pool profile, HAC in Figs. 3 and 5, augmenting with it the volume of the crucible and its productivity. No effect was detected in relation with the inclination of the walls, HAC2, HAC4 and HAC5 in Figs. 3 and 5, although normal practice prefers vertical walls. The introduction of stairs in the walls enhances the central pool profile; this effect can be attributed to the location of inactive coke towards the corner causing the effect of a floating dead man, models HAC4 and HAC5 in Figs. 3 and 5.

Modelling the chemical attack to refractory is based on the thermal equilibrium reached between the iron and the refractory; the temperature of $1150^{\circ} \mathrm{C}$, which corresponds to the $\mathrm{Fe}-\mathrm{C}$ eutectic, is taken as a reference to account for the damage of carbonaceous materials, The case for systems based in $\mathrm{Al}_{2} \mathrm{O}_{3}-\mathrm{SiO}_{2}$, which various degrees of nitriding, does not have such a characteristic temperature. ${ }^{21,22)}$ NWM indicates that the corrosion rate at the molten metal interface is reduced to zero when the thermodynamic equilibrium among the different phases is achieved; in such a case, wear of the crucible stops and the possibility for developing protecting layers is enhanced.

NWM can be used to evaluate the effect of different operational parameters on the rate of corrosion; among the variables to study are the bulk temperature of the iron, $T^{\infty}$, and the position of the dead man, see Fig. 6. NWM can also be used to analyze the effect ilmenite, $\mathrm{FeO} \cdot \mathrm{TiO}_{2}$, added to prolong the operational life of blast furnaces. ${ }^{23,24)}$ NWM has analyzed the case of using different grades of carbonaceous materials in a blast furnace, as it is model HAB3 in Figs. 2 and 4, which is not attempted at an industrial level, as the results shown in Fig. 4 indicate how the side with the material of lower thermal conductivity is subjected to higher wear. It is frequent to observe that bricks made of different materials are located within the wall of 


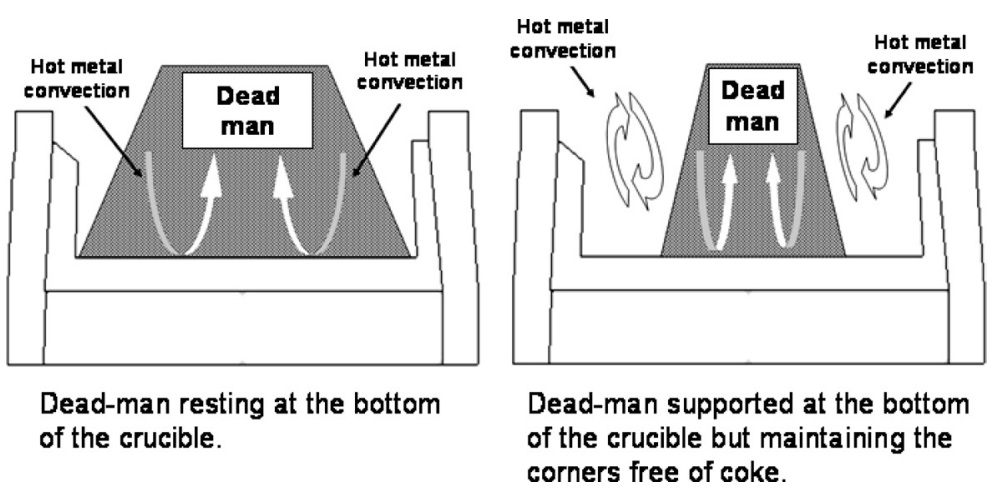

Fig. 6. Different layouts of the dead man in the blast furnace crucible.

blast furnaces to study their behaviour, but the conclusions from such studies may be erroneous, especially in the case in which materials with marked differences in thermophysical properties.

The use of different layers in furnaces is based on the possibility of using corrosion resisting materials in contact with molten iron, while isolating layers reduce thermal losses. From this point of view, the optimum design will be that in which minimum values of $T_{i}$ and $\Delta T_{i}$, are achieved while the difference of $T^{\infty}-T_{i}$ is maximized. ${ }^{25}$ )

\section{Conclusions}

The conditions for incrementing the life of blast furnaces are justified on terms of the heat extracted from walls or bottom of the crucible either by using high conductivity materials or refrigeration. Assuring high values of $T^{\infty}-T_{i}$ implies low nodal temperatures at the molten metal-refractory interface, $T_{i}$, and, consequently, the differences between adjacent nodes, $\Delta T_{\mathrm{i}}$, is reduced.

NWM predictions indicate that the occurrences of mushroom or elephant foot profiles are eliminated by an adequate disposition of high conductivity refractory materials. The use of high conductivity materials at the corners of the hearth enhances the central pool profile, which reduces the risk of perforation while increases the productivity of the furnace.

NWM shows that the temperatures at the interface are critical, but these values are difficult to obtain, and this tool can be used in conjunction with traditional measurements carried out in the bulk or in the slag to improve the operation of blast furnaces.

Care has to be taken when using corrosion rates from static tests, as NWM shows that rates occurring within the blast furnaces are much reduced than those observed in static tests, and that the corrosion rate diminishes with time.

\section{Acknowledgement}

The authors acknowledge the support from the Ministry for Education and Science (MEC) of Spain for the support provided by to the project MAT2003-00502, to the Ministry for Foreign Affairs and Cooperation (MAEC) of Spain for the support to the projects MAEC-AECI-B/1629/04, B/2884/05 and B/5814/06, and to the Group Saint-Gobain C.R.E.E.-Cevaillon Cedex, France, for their help and support to this work.

\section{REFERENCES}

1) L. F. Verdeja, J. P. Sancho and J. I. Verdeja: CIM Bull., 95 (2002), 88.

2) W. Kowalski, H. B. Lüngen and K. P. Stricker: Rev. Metall., Cah. Inf. Tech., 97 (2000), 493.

3) J. L. Barranzuela Queneche: Ph. D. Thesis, Universidad de OviedoEspaña, Departamento de Ciencia de los Materiales e Ingeniería Metalúrgica, (2000).

4) M. F. Barbés Fernández: Ph. D. Thesis, Universidad de OviedoEspaña, Departamento de Ciencia de los Materiales e Ingeniería Metalúrgica, (2004).

5) L. F. Verdeja, R. Parra, J. P. Sancho and J. Bullón: ISIJ Int., 43 (2003), 192.

6) C. Goñi Alarcón: Ph. D. Thesis, Programa de Postgrado de la Universidad de Concepción-Chile, Facultad de Ingeniería, Departamento de Ingeniería Metalúrgica, (2004).

7) C. Goñi, M. F. Barbés, V. Bazán, E. Brandaleze, R. Parra, L. F. Verdeja: J. Ceram. Soc. Jpn., 114 (2006), 665.

8) K. Shibata, Y. Kimura, M. Shimizu and S. Inaba: ISIJ Int., 30 (1990), 208.

9) K. Takatani, T. Inada and K. Takata: ISIJ Int., 41 (2001), 1139.

10) J. Jung and S. Kim: Steel Res., 72 (2001), 125.

11) B. Wright, P. Zulli, F. Bierbrauer and V. Panjkovic, V.: Proc. of the 3rd Int. Conf. on CFD in the Minerals and Process Industries, CSIRO, Melbourne, (2003), 645.

12) L. F. Verdeja, A. Alfonso and R. González: Am. Ceram. Soc. Bull., 77 (1998), 91.

13) L. F. Verdeja, R. González and A. Ordóñez: JOM, 52 (2000), No. 2, 74.

14) L. F. Verdeja, P. Rusek, A. Alfonso and R. González: Rev. Metal. Madrid, 34 (1998), 175.

15) H. J. Bachhofen, H. P. Rüther, M. Peters, T. Rödl, T. Thiemann and K. Marx: Stahl Eisen, 119 (1999), No. 9, 51.

16) K. Mülheims, R. Fusenig, W. D. N. Pritchard, P. Drake, J. M. Steiler, M. J. Venturini, S. A. Zaïmi, M. Schulte and M. Voss: Wear of Blast Furnace Hearth, EUR 20109 EN, European Commission, (2000).

17) R. McNally, F. Roulet, D. Kuster, J. Schoennahl and D. Lucke: Advances and Advantages with Ceramic Cup Thechnology, ALAFARMéxico, (2000), Industrial Ceramic, 16.

18) L. F. Verdeja, R. Parra, M. F. Barbés, Ch. Goñi and V. Bazán: Steel Grips, 3 (2005), 105.

19) J. Piret, J. L. Menéndez, M. Franken and P. Blumenfeld: Study of Behavior of Cement and Mass Joints Utilized in Aggregates of the Steel Industry, EUR 21133 EN, European Commission (2004), 167.

20) R. R. Landreth, M. G. Ranade: 58th Ironmaking Conf. Proc. ISS, Warrendale, PA, (1999), 669.

21) T. P. Fredman: Can. Metall. Q., 41 (2002), 475.

22) S. A. Zaïmi, M. Picard, M. J. Venturini, J. L. Eymond, C. Franssen, G. Masson and J. M. Dyrda: Proc. 25 Journées Sidérurgiques Internationales, Blast Furnace, ATS-Paris, (2004), 10.

23) J. A. Pereira-Novaes, R. da Cruz, Jr., M. Correa da Silva, J. I. Gushiken, R. J. Tauffer Barros and M. Azevedo de Oliveira: Rev. Metall., Cah. Inf. Tech., 102 (2005), 183.

24) C. A. Klein, R. G. Rezende, F. Kaoru and J. Issamu: Stahl Eisen, 125 (2005), No. 6, S13.

25) R. Parra, L. F. Verdeja, M. F. Barbés, Ch. Goñi and V. Bazán: JOM, 57 (2005), No. 10, 29. 